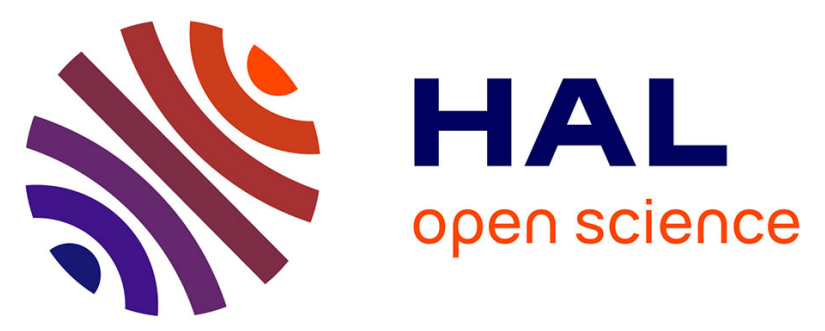

\title{
Switching On/Off the Chemisorption of Thiocticbased Self-Assembled Monolayers on Gold by Applying a Moderate Cathodic/Anodic Potential
}

Rihab Sahli, Claire Fave, Noureddine Raouafi, Khaled Boujlel, Bernd

Schöllhorn, Benoît Limoges

\section{To cite this version:}

Rihab Sahli, Claire Fave, Noureddine Raouafi, Khaled Boujlel, Bernd Schöllhorn, et al.. Switching On/Off the Chemisorption of Thiocticbased Self-Assembled Monolayers on Gold by Applying a Moderate Cathodic/Anodic Potential. Langmuir, 2013, 29 (17), pp.5360-5368. 10.1021/la401117u . hal-03271717

\section{HAL Id: hal-03271717 \\ https://hal.science/hal-03271717}

Submitted on 27 Jun 2021

HAL is a multi-disciplinary open access archive for the deposit and dissemination of scientific research documents, whether they are published or not. The documents may come from teaching and research institutions in France or abroad, or from public or private research centers.
L'archive ouverte pluridisciplinaire HAL, est destinée au dépôt et à la diffusion de documents scientifiques de niveau recherche, publiés ou non, émanant des établissements d'enseignement et de recherche français ou étrangers, des laboratoires publics ou privés. 


\section{Switching On/Off the Chemisorption of Thioctic-}

\section{based Self-Assembled Monolayers on Gold by}

\section{Applying a Moderate Cathodic/Anodic Potential}

Rihab Sahli, ${ }^{a, c}$ Claire Fave, ${ }^{a, b}$ Noureddine Raouafi, ${ }^{c}$ Khaled Boujlel, ${ }^{c}$ Bernd Schöllhorn, ${ }^{a, *}$ and Benoît Limoges ${ }^{a, *}$

aababoratoire d'Electrochimie Moléculaire, UMR CNRS 7591, and ${ }^{b}$ Institut de Topologie et de Dynamique des Systèmes (ITODYS), UMR 7086 CNRS, Université Paris Diderot, Sorbonne Paris Cité, 15 rue Jean-Antoine de Baïf, F-75205 Paris cedex, France.

${ }^{\mathrm{c}}$ Laboratoire de Chimie Analytique et d'Electrochimie, Département de Chimie, Faculté des Sciences de Tunis, Université El-Manar, 2092 Tunis El-Manar, Tunisia. 


\begin{abstract}
An in situ and real time electrochemical method has been devised for quantitatively monitoring the self-assembly of a ferrocene-labeled cyclic disulphide derivative (i.e., a thioctic derivative) on a polycrystalline gold electrode under electrode polarization. Taking advantage of the high sensitivity, specificity, accuracy and temporal resolution of this method, we were able to demonstrate an unexpectedly facilitated formation of the redox-active SAM when the electrode was held at a moderate cathodic potential $\left(-0.4 \mathrm{~V} v s\right.$. SCE in $\left.\mathrm{CH}_{3} \mathrm{CN}\right)$, affording a saturated monolayer from only micromolar solutions in less than $10 \mathrm{~min}$, and a totally impeded SAM growth when the electrode was polarized at a slightly anodic potential $(+0.5 \mathrm{~V} v s$. SCE in $\left.\mathrm{CH}_{3} \mathrm{CN}\right)$. This method literally allows for switching on/off the formation of SAMs under "soft" conditions. Moreover the cyclic disulphide-based SAM was completely desorbed at this potential contrary to the facilitated deposition of a ferrocene-labeled alkanethiol. Such a strikingly contrasting behavior could be explained by an energetically favored release of the thioctic-based SAM through homolytic cleavage of the Au-S bond followed by intramolecular cyclization of the generated thiyl diradicals. Moreover, the absence of a discernible transient faradaic current response during the potential-assisted adsorption/desorption of the redox-labeled cyclic disulphide led us to conclude in a potential-dependent reversible surface reaction where no electron is released or consumed. These results provide new insights into the formation of disulfide-based SAMs on gold, but also raise some fundamental questions about the intimate mechanism involved in the facilitated adsorption/desorption of SAMs under electrode polarization. Finally, the possibility to easily and selectively address the formation/removal of thioctic-based SAMs on gold by applying a moderate cathodic/anodic potential offers another degree of freedom in tailoring their properties and in controlling their self-assembly, nanostructuration, and/or release.
\end{abstract}




\section{INTRODUCTION}

Spontaneous chemisorption of sulphur containing molecules from solution onto metal gold surface (i.e., by simple immersion of a bare gold surface in a diluted solution of the sulphur compound) is certainly the most popular and widely used method for preparing stable and oriented self-assembled monolayers (SAMs) ${ }^{1-4}$ However several important issues have been identified. It is well recognized that it is difficult to reproducibly prepare sulphur-based SAMs on gold with identical properties and in a predicable manner, although scrupulously identical preparation conditions may have been used..$^{5}$ It has also been established that the formation and quality of SAMs is strongly dependent on a wide range of experimental parameters such as the solvent used during the chemisorption process, the mass transport setting, the adsorption temperature, the adsorbate concentration, the cleanliness, chemical composition and/or structure of the gold surface (i.e., degree of gold crystallinity, surface roughness, presence of gold oxides, defects, impurities and/or contaminations), and the immersion time (including annealing and/or aging time). ${ }^{1-4,6,7}$ Other important factors such as the type of sulphur function (i.e., thiol, sulphide, disulphide, dithiocarbamate) used to bind the metal and the chain length connected to the sulphur anchoring group add to the numerous parameters involved in SAM preparation, rendering thus particularly difficult the selection of an appropriate procedure. Another important concern is the slowness of the spontaneous self-assembly process, which may require immersion times of hours or even days in millimolar concentrations of the adsorbate for producing wellpacked and ordered monolayer films. ${ }^{6,7,8-11}$

The development of alternative methods for preparation of SAMs with improved quality, reproducibility, within shorter time and in a more predicable manner is thus an important issue. One interesting approach which has been so far only marginally explored, consists to control the 
self-assembly of alkanethiols on gold by the electrode potential. ${ }^{12-15}$ For example, Ma and Lennox have shown that a moderate anodic potential (ranging from +0.2 to $+0.6 \mathrm{~V} v s . \mathrm{Ag} / \mathrm{AgCl}$ ) applied to a gold electrode in a solution of $n$-alkylthiols or a mixture of $n$-alkylthiols in ethanol leads quickly (in less than 15 min instead of hours under open circuit potential) to a saturated close-packed monolayer with excellent blocking properties against free diffusing redox probes in solution. ${ }^{12}$ There is however no clear mechanism for explaining this phenomenon. The Paik's group has proposed that the facilitated formation of SAMs from $n$-alkanethiols under electrode polarization results from an electrochemical oxidation during which gold surface atoms are oxidized as the metal-sulphur bonds are formed, resulting in a net anodic current. ${ }^{16,17}$ The same authors have also explored the potential-assisted formation of SAMs from dialkyl disulfides ${ }^{*}$ and, on the basis of the transient cathodic currents at a gold electrode held at $0 \mathrm{~V}(v s . \mathrm{Ag} / \mathrm{AgCl})$ subsequent to the injection of millimolar dipropyl disulphide solutions, they stated that, conversely to $n$-alkanethiols, dialkyl disulfides adsorb through an electrochemical reaction that results in a net cathodic current. ${ }^{16,17}$ These assertions are however uncertain because the transient currents observed during injection of thiol or disulphide could simply arise from a change and/or perturbation of the double layer charging current (vide infra). Moreover, the transient peak currents were poorly reproducible (some of them showing fluctuations and multiple spikes), integrations did not well-match the faradaic charge required for a monolayer deposition, and the current did not increase simultaneously with the recorded mass increase by quartz crystal microgravimetry. ${ }^{16}$

To get better insight into the effect of an applied potential during the formation of SAMs from disulphide derivatives and in an attempt to clarify the underlying kinetics and mechanism, we have here investigated the potential-assisted deposition of a redox-labeled cyclic disulphide 
on a polycrystalline gold electrode in acetonitrile. As a prototypical cyclic disulphide, we have selected the 5-(1,2-dithiolan-3-yl)pentanol, a thioctic acid derivative which, thanks to its two sulphur anchoring groups, displays a significantly stronger binding affinity to gold than the corresponding monopodal acyclic disulfides or thiols. ${ }^{18-21}$ The 5-(1,2-dithiolan-3-yl)pentanol was coupled through its terminal -OH function to a redox-active ferrocenoyl group, leading to $(1,2-$ dithiolan-3-yl)pentyl ferrocenecarboxylate ester $\left(\mathrm{FcCO}_{2} \mathrm{DT}\right.$ in Figure 1). On account of the presence of the one-electron reversible redox probe, one can anticipate that the $\mathrm{FcCO}_{2} \mathrm{DT}$ selfassembly can be in situ electrochemically monitored at a polarized gold electrode.

The use of redox-labeled alkanethiols for the electrochemical determination of SAM formation kinetics is not unprecedented ${ }^{22-23}$ but, to the best of our knowledge, it has never been proposed for an in situ and real time monitoring of SAM growth. Compared to other in situ surface sensitive methods such as quartz crystal microbalance, ${ }^{9}$ surface plasmon resonance, ${ }^{10}$ surface conductance, ${ }^{24}$ or second harmonic generation, ${ }^{25}$ the electrochemical approach could selectively distinguish surface excess of adsorbate from unrelated adsorbed species such as solvent or ions. It is also an accurate and sensitive method since fractional coverage as low as $0.2 \%$ of a redox-active monolayer could be routinely detected by cyclic voltammetry $(\mathrm{CV}) .{ }^{26}$ Another significant advantage of the electrochemical method stems from its short time resolution, potentially authorizing an in situ monitoring of SAM growth by CV with a temporal resolution in the order of seconds (vide infra) or even less.

\section{RESULTS}

Before studying the self-assembly of $\mathrm{FcCO}_{2} \mathrm{DT}$ on gold, the electrochemical behavior of a homogenous solution of $\mathrm{FcCO}_{2} \mathrm{DT}$ was examined by $\mathrm{CV}$ at a glassy carbon electrode (Figure 1). 
As expected, the CV shows a well-defined one-electron diffusion-controlled reversible wave centered at a standard potential of $E^{0}=+0.66 \mathrm{~V}$, representative of the ferrocenoyl group. The reversible wave is accompanied by two irreversible diffusion-CONTROLLED peaks, one localized at a high cathodic potential $\left(E_{p, c}=-2.0 \mathrm{~V}\right)$ and the other at a high anodic value $\left(E_{p, a}=\right.$ $+1.16 \mathrm{~V})$. These two irreversible waves are characteristic of the reductive and oxidative cleavage of the disulphide bond, respectively. ${ }^{27,28}$ It is noteworthy that their intensities are $1.2-1.3$-fold higher than the anodic or cathodic peak current of the reversible wave of ferrocenoyl, suggesting that more than one electron is involved in both the reductive and oxidative process. ${ }^{27,28}$

In situ monitoring of the $\mathrm{FcCO}_{2} \mathrm{DT}$ self-assembly on gold was performed as follows. A freshly polished polycrystalline disk gold electrode is immersed in a diluted solution of $\mathrm{FcCO}_{2} \mathrm{DT}$ in $0.1 \mathrm{M} \mathrm{TBABF}_{4} / \mathrm{CH}_{3} \mathrm{CN}$ (beforehand carefully deaerated by argon bubbling) and then held at the desired potential $\left(E_{\text {appl. }}\right)$ for a given period of time in a non-agitated solution. The amount of chemisorbed $\mathrm{FcCO}_{2} \mathrm{DT}$ on gold is then sampled by a fast $\mathrm{CV}$ scan (starting AND final potentials were equal to $E_{\text {appl. }}$ ) at regular time intervals during polarization (typically every $13 \mathrm{~s}$ ). A scan rate $(\mathrm{v})$ of $10 \mathrm{~V} / \mathrm{s}$ was selected so that the $\mathrm{CV}$ acquisition time remains negligible $(0.25 \mathrm{~s})$ compared to the polarization time intervals. Moreover, as the $\mathrm{FcCO}_{2} \mathrm{DT}$ concentration was in the micromolar range (i.e., $\leq 20 \mu \mathrm{M}$ ), the voltammetric contribution of the free-to-diffuse $\mathrm{FcCO}_{2} \mathrm{DT}$ molecules in solution represents an insignificant fraction of the total current measured, allowing thus the adsorption progress to be in situ determined by measuring the charge under the voltammetric peaks of chemisorbed $\mathrm{FcCO}_{2} \mathrm{DT}$. Different applied potentials localized within the potential window of $-0.5 \mathrm{~V}$ to $+0.5 \mathrm{~V}$ (vs. SCE) were selected. As it can be seen in Figure 1, $\mathrm{FcCO}_{2} \mathrm{DT}$ does not lead to any electrochemical reduction or oxidation in acetonitrile within this potential window. 


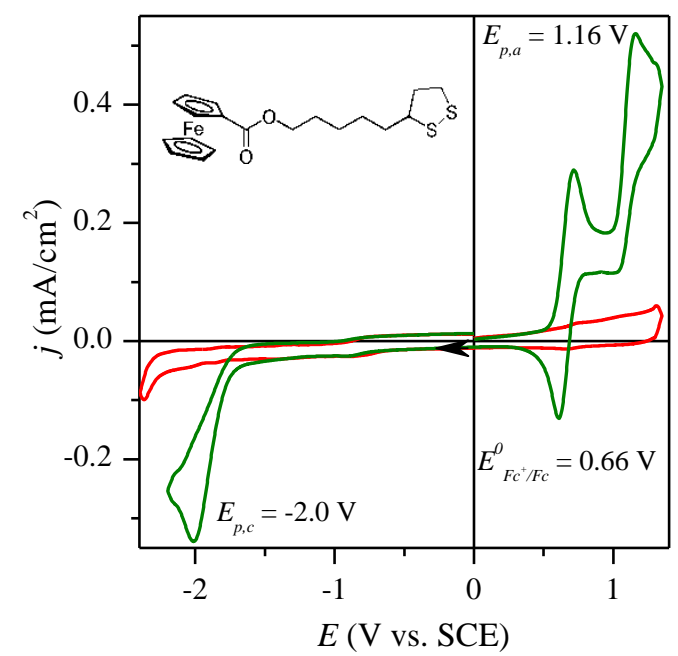

Figure 1. $\mathrm{CV}$ of $\mathrm{FcCO}_{2} \mathrm{DT}\left(1 \mathrm{mM}\right.$ in $\left.0.1 \mathrm{M} \mathrm{TBABF} / \mathrm{CH}_{3} \mathrm{CN}\right)$ at a glassy carbon electrode. Scan rate: $0.1 \mathrm{~V} / \mathrm{s}$. The red plot corresponds to the $\mathrm{CV}$ blank response before the addition of $\mathrm{FcCO}_{2} \mathrm{DT}$.

A typical series of CVs recorded at a gold electrode held at a slightly cathodic potential of $-0.4 \mathrm{~V}$ in $1 \mu \mathrm{M}$ solution of $\mathrm{FcCO}_{2} \mathrm{DT}$ is shown in Figure $2 \mathrm{~A}$. The growing of a well-defined reversible pair of symmetric peaks, characteristic of the ferrocene/ferrocenium couple, can be clearly discerned at the formal potential $E^{0^{\prime}}=+0.70 \mathrm{~V} .^{\S}$ Analysis of the anodic or cathodic peak currents as a function of the scan rate shows a linear dependence (Figure S1 in Supporting Information), which is typical of a surface-confined electroactive centre. The $\mathrm{FcCO}_{2} \mathrm{DT}$ surface concentration $\left(\Gamma_{F_{c}}\right)$ as a function of electrode polarization time $(t)$ was obtained by integration of the charge under the anodic peak current of ferrocene (i.e., after baseline subtraction) and considering a one-electron exchanged per molecule of $\mathrm{FcCO}_{2} \mathrm{DT}$. The resulting adsorption kinetic plot (Figure 2E, blue curve) shows a linear increase of the ferrocene surface concentration over the first $600 \mathrm{~s}$, followed by an asymptotic growth at longer time scale, reaching a limiting value of $3.7 \times 10^{-10} \mathrm{~mol} / \mathrm{cm}^{-2}$ after more than $30 \mathrm{~min}$.

This limiting value is close to the theoretical maximum coverage that can be calculated for densely-packed ferrocene head groups on a flat solid surface (i.e., $4.5 \times 10^{-10} \mathrm{~mol} / \mathrm{cm}^{-2}$ ). ${ }^{29}$ This 
is also in fairly good agreement with the value of $3.5 \times 10^{-10} \mathrm{~mol} / \mathrm{cm}^{-2}$ previously found for a saturated monolayer of a nitrilotriacetic-thioctic acid derivative on a polycrystalline gold electrode. ${ }^{26}$ To definitely demonstrate that a saturated coverage was reached, the experiment was repeated for a higher solution concentration of $20 \mu \mathrm{M} \mathrm{FcCO} 2 \mathrm{DT}$ (Figure 2E, red curve). Under these conditions, the steady-state coverage was reached in a shorter time $(<8 \mathrm{~min})$, demonstrating a concentration dependence of the chemisorption rate (a $\sim 20$-fold increase of the initial adsorption rate was obtained when passing from 1 to $20 \mu \mathrm{M} \mathrm{FcCO} 2 \mathrm{DT}$ ). The limiting coverage value was nearly the same than at $1 \mu \mathrm{M}$, indicating that a saturated close-packed monolayer of $\mathrm{FcCO}_{2} \mathrm{DT}$ was formed on gold.

At a scan rate of $1 \mathrm{~V} / \mathrm{s}$ (Figure S2), the electrochemical behavior of the saturated redoxactive SAM is remarkably close to that theoretically expected for an ideal Nernstian redox species adsorbed on an electrode surface (i.e., the peak-to-peak potential separation, $\Delta E_{p}$, differs by less than $13 \mathrm{mV}$ and the fwhm for each peak was $102 \mathrm{mV}$, close to the theoretical values of $\Delta E_{p}=0 \mathrm{mV}$ and fwhm $=89 \mathrm{mV}$ at $\left.20^{\circ} \mathrm{C}\right) .{ }^{30}$ Such nearly ideal behavior suggests few interactions between the immobilized ferrocene/ferrocenium molecules and a relatively high homogeneity around the redox centre and thus of the redox-active SAM layer, reflecting the high degree of self-organization afforded by the potential-assisted deposition method. The possibility to reach a saturated SAM monolayer from an only $1 \mu \mathrm{M}$ disulphide solution is another remarkable result.

To verify that the CV sampling at each time interval (13 s) does not influence or perturb the adsorption process, we have tested lower CV sampling frequency (ranging from $60 \mathrm{~s}$ to $10 \mathrm{~min}$ ) and the resulting kinetic plots were the same. Concomitantly to the increase of the ferrocene peak currents during SAM formation, the capacitive current decreases with time (Figure 2A). By plotting the capacitance density (obtained from the anodic capacitive current at $+0.45 \mathrm{~V}$ ) as a 

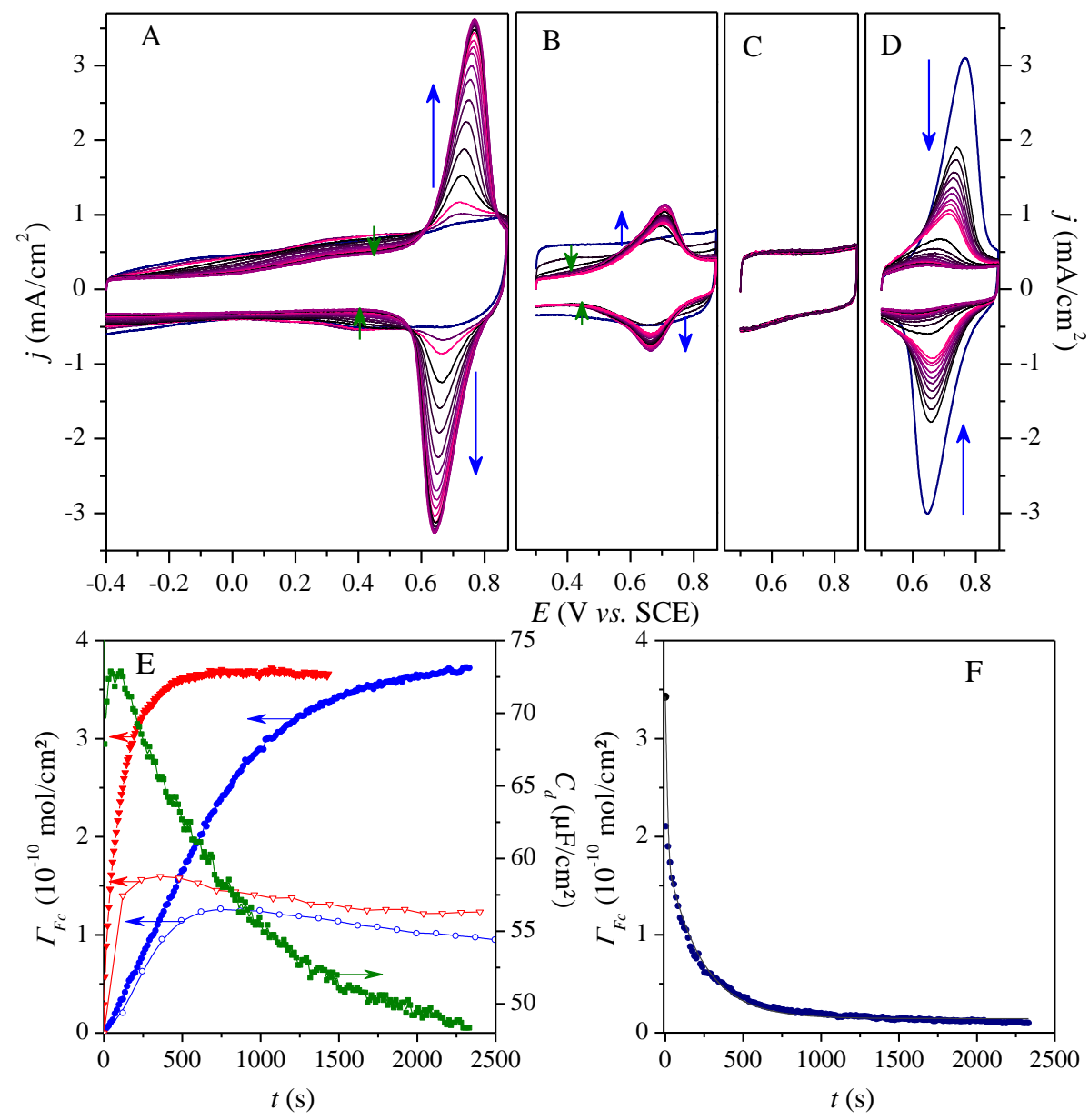

Figure 2. (A) CVs $(v=10 \mathrm{~V} / \mathrm{s})$ periodically recorded at a gold electrode held at $E_{\text {appl. }}=-0.4 \mathrm{~V}(v s . \mathrm{SCE})$ in a $1 \mu \mathrm{M} \mathrm{FcCO}_{2} \mathrm{DT}$ (in $0.1 \mathrm{M} \mathrm{TBABF} / \mathrm{CH}_{3} \mathrm{CN}$ ). The first $\mathrm{CV}$ was recorded after $5 \mathrm{~s}$ of electrode polarization and the last one after $39 \mathrm{~min}$ (the $\mathrm{CVs}$ were recorded every $13 \mathrm{~s}$, but for clarity only scans numbered $1,5,10,20,30,40,50,60,70,80,90,100,110,120,130,140$, $150,160,170$, and 180 are shown). (B) Same as in A, but without electrode polarization (each CV scan was recorded every $125 \mathrm{~s}$ at $v=10 \mathrm{~V} \mathrm{~s}^{-1}$ ). (C) Same as in A but for a gold electrode held at $E_{a p p l .}=+0.5 \mathrm{~V}$. (D) After the last scan in A, the SAM-modified gold electrode was transferred in a pure $0.1 \mathrm{M} \mathrm{TBABF}_{4} / \mathrm{CH}_{3} \mathrm{CN}$ and poised at $E_{\text {appl. }}=+0.5 \mathrm{~V}$ for 39 min, while a CV scan was periodically sampled every $13 \mathrm{~s}$ (i.e., same CV sampling procedure than in A). For clarity, only scans numbered 0, 1, 2, 3, 4, 5, 6, $7,8,10,20,30,40,50,60,70,80,90,100,110,120,130,140,150,160,170$, and 180 are shown (the scan 0 was acquired just before the electrode was poised at $+0.5 \mathrm{~V}$ ). In $\mathrm{A}, \mathrm{B}$ and $\mathrm{D}$, the green and blue arrows indicate, respectively, the progress of the capacitive and faradaic current responses as a function of time. (E) Kinetic plots showing the progress of (blue and red plots) $\Gamma_{F c}$ and (green plot) $C_{d}$ as a function of time in a solution of $(\bullet, \mathrm{O}, \boldsymbol{\nabla}) 1 \mu \mathrm{M}$ or $(\boldsymbol{\nabla}, \nabla) 20 \mu \mathrm{M} \mathrm{FcCO} \mathrm{DT}_{2}$ and for an electrode $(\bullet, \nabla$, च) held at $-0.4 \mathrm{~V}$ or $(\mathrm{O}, \nabla)$ under OCP. (F) Desorption kinetic plot at $+0.5 \mathrm{~V}$ resulting from the integration of the anodic peak currents in D. Black curve: double-exponential decay fit. 
function of polarization time (Figure 2E), a good correlation is obtained between the direct monitoring of SAM growth via the redox probe and its indirect tracing through the capacitance density measurement (Figure S3). The kinetic plots based on the capacitance measurement are however much less well-defined and resolved that the plots based on CV measurement, clearly illustrating the relevance of the in situ electrochemical detection of a redox-labeled SAM

In order to compare the SAM formation under controlled potential to conventional passive adsorption (i.e., without electrode polarization), the experiment was repeated at a freshly polished gold electrode immersed in a $1 \mu \mathrm{M}$ or $20 \mu \mathrm{M}$ solution of $\mathrm{FcCO}_{2} \mathrm{DT}$ under open circuit potential (OCP). The surface coverage was then determined, as previously, from fast $\mathrm{CV}$ scans $(10 \mathrm{~V} / \mathrm{s})$ repeated at regular time intervals (Figure 2B). As a precaution, a longer time interval of $125 \mathrm{~s}$ was selected to avoid any possible impact of CV scans on the SAM formation. The resulting CVs (Figure 2B) and adsorption kinetic profiles (Figure 2E) show that, regardless of comparable adsorption rates at the early stage of SAM formation, values of ferrocene peak intensities were much lower than those obtained under applied potential, reaching a maximum coverage of only ca. one-third of that obtained under the slightly cathodic applied potential (i.e., $\Gamma_{F c}=1.25 \times 10^{-10} \mathrm{~mol} / \mathrm{cm}^{-2}$ at $1 \mu \mathrm{M}$ and $\Gamma_{F_{c}}=1.55 \times 10^{-10} \mathrm{~mol} / \mathrm{cm}^{-2}$ at $\left.20 \mu \mathrm{M}\right)$. This result clearly demonstrates the beneficial effect of a slightly cathodic applied potential to the SAM formation. It also illustrates that, under OCP and low disulphide concentrations, saturated coverage could not be reached. This latter observation suggests that the chemisorption process is governed by an apparent equilibrium binding and not by an irreversible binding reaction as it is often assumed for the chemisorption of sulphur-containing molecules on gold surfaces. ${ }^{9,10,24}$ The data also suggest that the effect of the applied potential look likes much more as a thermodynamic control on the adsorption reaction than a stimulus on the binding kinetics, in 
other worlds the applied potential at $-0.4 \mathrm{~V}$ is able to enhance the affinity binding of $\mathrm{FcCO}_{2} \mathrm{DT}$ for the gold surface.

The effect of a moderate anodic applied potential during SAM formation was next examined with a gold electrode held at $+0.5 \mathrm{~V}$ (Figure $2 \mathrm{C}$ ). In stark contrast to the former results at $-0.4 \mathrm{~V}$ and whatever the polarization time, no ferrocene signal could be observed in the $\mathrm{CV}$, showing only a stable capacitive baseline current with time. The experiment was repeated at a higher concentration of $20 \mu \mathrm{M} \mathrm{FcCO} 2 \mathrm{DT}$ and the same result was obtained (Figure $3 \mathrm{~A}$ ). This behavior was rather unexpected because in total contrast to the facilitated formation of SAM from $n$-alkanethiols using similar anodic applied potentials. ${ }^{12}$ Such a drastic effect has not been described by Paik and coll. It is likely that, at the low concentration of $\mathrm{FcCO}_{2} \mathrm{DT}$ we have used, it is easy to discriminate the potential-assisted SAM growth from the spontaneous SAM formation, which is no more the case at the millimolar dipropyl disulphide concentrations used by Paik and coll. ${ }^{16,17}$ Such a contrasting behavior is also likely related to a different potentialassisted adsorption/desorption mechanism between cyclic disulfides and acyclic disulfides.

The lack of $\mathrm{FcCO}_{2} \mathrm{DT}$ adsorption at $+0.5 \mathrm{~V}$ suggested that the corresponding disulphidebased SAM could be desorbed at this potential. To verify this hypothesis, a gold electrode covered by a saturated monolayer of $\mathrm{FcCO}_{2} \mathrm{DT}$ was transferred in a pure solution of $0.1 \mathrm{M}$ $\mathrm{TBABF}_{4} / \mathrm{CH}_{3} \mathrm{CN}$ and then periodically scanned by $\mathrm{CV}$ while an electrical potential of $+0.5 \mathrm{~V}$ was applied (Figure 2D). As expected, the reversible peaks of ferrocene rapidly decreased as a function of polarization time, whereas the initial formal potential centered on $E^{0^{\prime}}=+0.70 \mathrm{~V}$, representative of the immobilized ferrocene probe, was progressively shifted to a potential value $+0.66 \mathrm{~V}$ characteristic of the standard potential of $\mathrm{FcCO}_{2} \mathrm{DT}$ in homogeneous solution (Figure 2D). It is important to note that the ferrocene signal decrease cannot be related to an instability or 
decomposition of the redox probe because at $+0.5 \mathrm{~V}$ the ferrocene remains in its highly stable reduced form. ${ }^{\dagger}$ The resulting desorption kinetics shown in Figure $2 \mathrm{~F}$ is characterized by a double-exponential decay with a fast primary desorption process during which more than half of the surface coverage is rapidly lost over the first few seconds, followed by a much slower exponential desorption rate over several tens of minutes. Clearly, the plot of desorption kinetics at $+0.5 \mathrm{~V}$ is distinct from the adsorption process at $-0.4 \mathrm{~V}$, indicating a different mechanism between the potential-assisted desorption and adsorption

In order to enlighten differences between the potential-assisted self-assembly of a cyclic disulphide and an alkanethiol on gold under a moderately applied anodic potential, the $\omega$ mercaptohexyl ferrocenecarboxylate ester was synthesized according to published procedures $\mathrm{s}^{31,32}$ and tested at $20 \mu \mathrm{M}$ using the same potential-assisted deposition/in situ measurement procedure as described above (i.e., $E_{\text {appl. }}=+0.5 \mathrm{~V}$ ). In stark contrast to the $\mathrm{CVs}$ reported in Figure $3 \mathrm{~A}$ for $\mathrm{FcCO}_{2} \mathrm{DT}$, the growth of a well-defined reversible wave of ferrocene was obtained as a function of polarization time (Figure 3B), confirming the results previously obtained by other groups for the potential-assisted deposition of alkanethiols in ethanol or aqueous buffer. ${ }^{12}$ After the SAM formation, the modified gold electrode was transferred in a pure $0.1 \mathrm{M} \mathrm{TBABF} / \mathrm{CH}_{3} \mathrm{CN}$ solution and tested for its stability by periodically scanning a fast $\mathrm{CV}$ while an electrical potential of +0.5 $\mathrm{V}$ was applied. After $25 \mathrm{~min}$ of electrode polarization, only a slight decrease $(\sim 15 \%)$ of the reversible wave of ferrocene could be observed, definitely demonstrating the contrasting behavior between an acyclic thiol and the cyclic disulphide. 


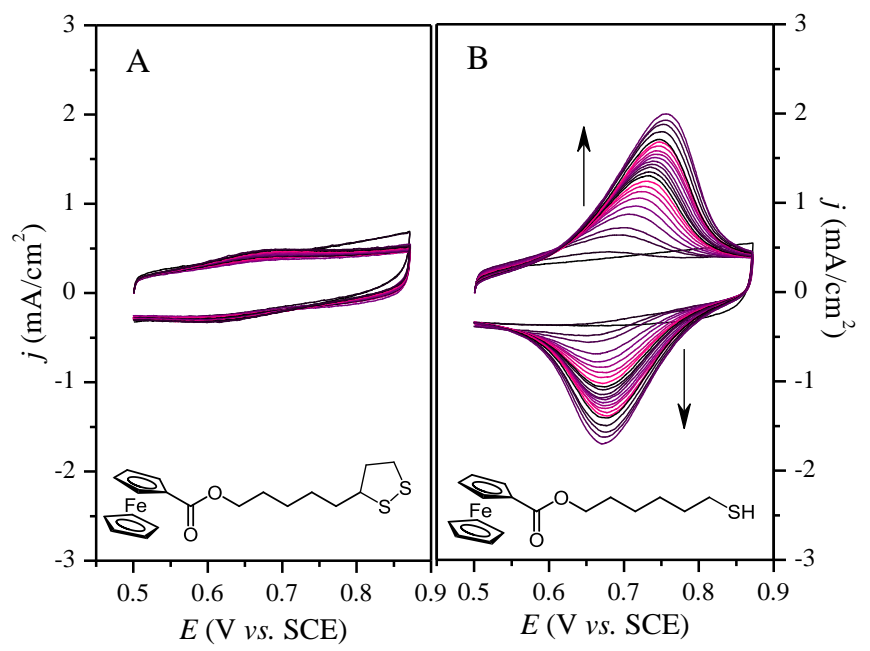

Figure 3. CVs $(v=10 \mathrm{~V} / \mathrm{s})$ periodically recorded at a gold electrode held at $E_{\text {appl. }}=+0.5 \mathrm{~V}$ in a (A) $20 \mu \mathrm{M} \mathrm{FcCO}_{2} \mathrm{DT}$ and $(\mathrm{B}) 20$ $\mu \mathrm{M} \omega$-mercaptohexyl ferrocenecarboxylate ester (in $0.1 \mathrm{M} \mathrm{TBABF} / \mathrm{CH}_{3} \mathrm{CN}$ ). $\mathrm{CV}$ s were recorded every $8 \mathrm{~s}$ during electrode polarization, but for clarity only scans numbered 1, 5, 10, 20, 30, 40, 50, 60, 70, 80, 90, 100, 110, 120, 130, 140, 150, 160, 170, $180,210,240,270$, and 300 are shown.

\section{DISCUSSIONS}

The obtained results raise some fundamental questions about the adsorption/desorption mechanism of disulfides and more specifically of cyclic disulfides. Electrochemical reductive and oxidative desorption of $n$-alkylthiol from gold is a well-known feature of SAMs, but it was reported to occur at highly cathodic $(<-1.0 \mathrm{~V} v s . \mathrm{SCE})^{33-37}$ and highly anodic potentials $(>+0.7$ V vs. SCE) ${ }^{38-40}$ Moreover, these processes were identified as electrochemical reactions leading to a net cathodic ${ }^{33-37}$ or anodic current. ${ }^{38}$ In the present case, the effect of the moderate electrode potentials on the SAM formation (or SAM desorption) appears to be completely different. Our results suggest an equilibrium reaction that can be tuned with the applied electrode potential. The spontaneous binding kinetics of sulphur-based compounds on gold is frequently kinetically described by an irreversible binding reaction process, ${ }^{25,41-44}$ where for disulfides the S-S bond is cleaved according to reaction (1), leading to the same RS-Au surface species as observed for thiols. $^{45-47}$ 


$$
2 \mathrm{Au}(0)+\mathrm{RS}-\mathrm{SR} \rightarrow 2 \mathrm{RS}-\mathrm{Au}(\mathrm{I})
$$

There is however evidence in literature that the spontaneous binding of sulphur compounds to gold may be related to an apparent equilibrium binding (in line with our observations in Figure $2 \mathrm{E}$ under $\mathrm{OCP}),{ }^{22,24,48-50}$ for which the reaction of chemisorption would be in competition with a back desorption reaction, leading to the release of a product that would correspond to a thiolate or a disulfide. ${ }^{24}$ The reversibility of the thiolate-metal bond also explains why SAMs of alkanethiolates can be thermally desorbed and undergo exchange with free thiols. ${ }^{45,46}$ On account of our results, we thus propose that the $\mathrm{FcCO}_{2} \mathrm{DT}$ chemisorption follows a potential-dependent equilibrium binding process which is displaced to the forward reaction (disulphide bond cleavage followed by Au-S bond formation) when the electrode potential is left at slightly cathodic value and, conversely, is switched back to the Au-S bond dissociation reaction when setting the electrical potential to a slightly anodic value. If we assume that the Au-S bond dissociation proceeds through homolytic cleavage, it is conceivable that, because of the energetically favored intramolecular reaction of cyclization, a preferred release of the disulphide product arises at +0.5 $\mathrm{V}$. This hypothesis is supported by the fact that no significant desorption of the redox-active SAM generated from the acyclic $\omega$-mercaptohexyl ferrocenecarboxylate ester could be observed at the same potential. The chemisorption reaction could thus be finally viewed as a potentialdependent reversible surface reaction (reaction 2) where no electron is released or consumed, which is fundamentally different to the mechanism previously proposed by Paik and coll. ${ }^{16,17}$

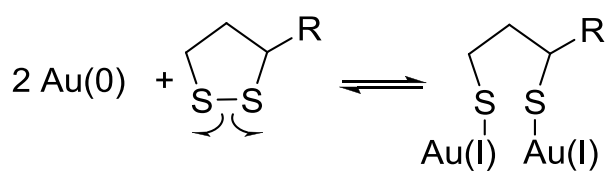


The absence of electrochemical reaction leading to a net flow of faradaic current during either SAM formation or SAM desorption is supported by the fact that, whatever the scan rate, we were unable to see any irreversible peak in CVs that would reflect an irreversible electrochemical oxidative desorption or reductive adsorption within the potential window of interest (this is not the case for the reductive desorption of $n$-alkylthiol SAMs from gold where a well-defined irreversible peak at highly negative potentials can be observed ${ }^{16,17}$ ). Moreover, no faradic response could be observed after stepping the potential of a bare gold electrode immersed in a $20 \mu \mathrm{M} \mathrm{FeCO} 2 \mathrm{DT}$ from +0.5 to $-0.4 \mathrm{~V}$ and also after stepping the potential of a saturated $\mathrm{FcCO}_{2} \mathrm{DT}$-SAM-coated gold electrode from -0.4 to $+0.5 \mathrm{~V}$ in a pure solution of $0.1 \mathrm{M}$ $\mathrm{TBABF}_{4} / \mathrm{CH}_{3} \mathrm{CN}$. In these cases, only a fast exponential decrease of the capacitive current was obtained (Figure S4). According to the large values of the capacitive current densities recorded during the potential step experiments, the possible low faradic current which would be associated to an electrochemical reductive adsorption or electrochemical oxidative desorption would be masked by the high values of the charging current. In order to evaluate the magnitude of the transient faradic current that would be recorded for a $2 \mathrm{e}^{-}$reaction per chemisorbed molecule, the double exponential fits of the kinetic plots in Figures $2 \mathrm{E}$ and $2 \mathrm{~F}$ were derived with respect to time and multiplied by the Faraday constant $(j=2 F d \Gamma / d t)$. The resulting faradic current densities as a function of time give maximal values of $1-2 \mu \mathrm{A} / \mathrm{cm}^{2}$ for both the adsorption and desorption processes (Figure S5), several order of magnitudes lower than the discharge of the capacitive current density (Figure S4). The faradic process, if existing, could thus not be discerned under the selected potential-step experimental conditions.

To definitively clarify whether a faradaic process is involved in the chemisorption of $\mathrm{FcCO}_{2} \mathrm{DT}$ under a slightly cathodic electrode polarization, the amperometric response of a gold 
electrode held at $-0.4 \mathrm{~V}$ in $0.1 \mathrm{M} \mathrm{TBABF} / \mathrm{CH}_{3} \mathrm{CN}$ was monitored during the course of a sudden injection of a disulphide solution into the electrochemical cell (final concentration of $100 \mu \mathrm{M}$ ). A control experiment including the injection of the electrolyte alone was also performed just before adding the disulphide. The resulting amperometric plots in Figure 4 show that, even for the injection of the electrolyte alone, transient peak currents were obtained. From repeated trials, it was found that these transient current responses were poorly reproducible, showing a strong dependence on the way the solution was injected into the electrochemical cell (sometimes showing a transient current and sometimes not). On average, more intense signals were measured following electrolyte injection than upon disulphide injection. The fact that transient current responses were obtained in the absence of $\mathrm{FcCO}_{2} \mathrm{DT}$ and also that, in its presence, the current changes were much lower than the predicted signal (green plot in Figure 4), clearly demonstrates that these current changes could not be attributed to a faradaic electrochemical reaction but rather to an uncontrolled disturbance of the double layer capacitive current following the injection of a solution into the electrochemical cell.

Repetitive on/off switch self-assembly of $\mathrm{FcCO}_{2} \mathrm{DT}$ on the gold electrode was finally tested. For such purpose the adsorption/desorption procedures used for the plots in Figure 2E and $2 \mathrm{~F}$ were iteratively repeated three times in a $1 \mu \mathrm{M} \mathrm{FcCO} 2 \mathrm{DT}$ solution. The resulting three adsorption/desorption kinetics plots were very similar, each leading to an on/off deposition of a saturated redox-active SAM on gold with a good reproducibility. It is interesting to note that after each SAM desorption at $+0.5 \mathrm{~V}$, the signal of ferrocene completely vanished, indicating that the gold electrode could be completely cleaned from the SAM, in situ, and then reused for a new deposition. This is a very appealing property that may be useful for electrically addressing 
the patterning of SAMs ${ }^{51-54}$ and for electrochemically modifying individually addressable electrodes in an interdigitated array, ${ }^{15,9,55-58}$ under "soft" conditions.

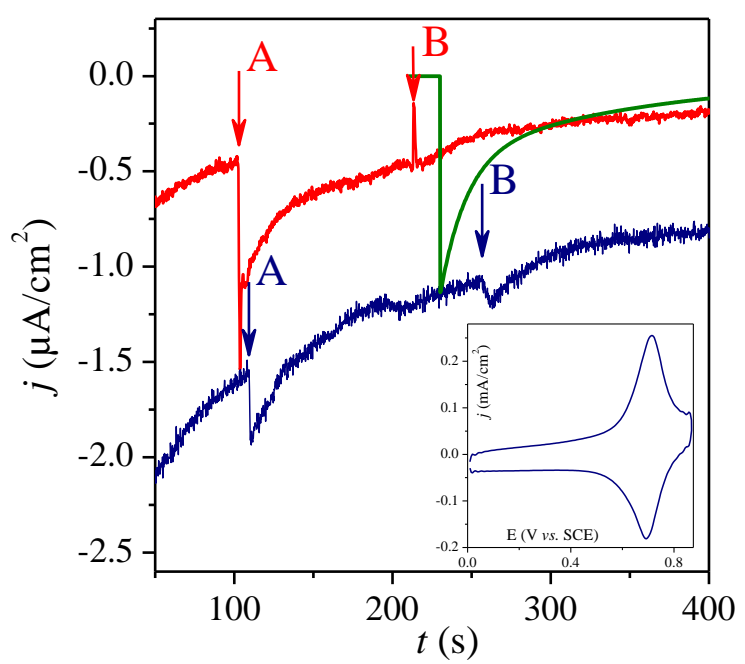

Figure 4. Amperometric responses (duplicated) recorded at a gold electrode held at $-0.4 \mathrm{~V}$ ( $v s$. SCE) in $6 \mathrm{~mL} 0.1 \mathrm{M}$ $\mathrm{TBABF}_{4} / \mathrm{CH}_{3} \mathrm{CN}$ during the successive addition of (A) $1 \mathrm{~mL} 0.1 \mathrm{M} \mathrm{TBABF}_{4} / \mathrm{CH}_{3} \mathrm{CN}$, followed by (B) $1 \mathrm{~mL}$ FcCO $\mathrm{DT}$ in $0.1 \mathrm{M}$ $\mathrm{TBABF}_{4} / \mathrm{CH}_{3} \mathrm{CN}$ (final concentration: $100 \mu \mathrm{M}$; final volume: $8 \mathrm{~mL}$ ). The green curve corresponds to the theoretical current response (the time position is arbitrary) that can be calculated from the red plot in Figure $2 \mathrm{E}$ involving $2 \mathrm{e}^{-}$exchanged per molecules adsorbed (see Figure S4). CV recorded (1 V/s) just after the amperometric experiment shown in blue.

Concerning the exact mechanisms of the chemisorption/desorption reactions and the influence of the electrical potential on these reactions, only speculative explanations can be proposed at the moment. A first possibility is that the applied potential contributes to lowering/increasing the activation energy for the Au binding process. If disulfides chemisorb on gold through homolytic cleavage of the S-S bond followed by formation of the Au-S bond, one can imagine that this process would be favored by a slightly cathodic polarization of gold. The inverse could be true in polarizing the electrode at a slightly anodic potential. A second possibility is that the electrode potential helps to initiate a radical chain transfer reaction through a homolytic cleavage of the disulphide bond, followed by an autocatalytic self-propagation of the generated thiyl radicals on the surface of the electrode coupled to SAM formation. This would be 
a process analogous to the radical-mediated disulphide fragmentation reaction recently proposed for the catalytic photodegradation of disulphide-based hydrogels (a only catalytic amount of electrons initiates the process, meaning that virtually no current could flow though the electrode) ${ }^{59}$ In preliminary experiments, we have tried to probe the formation of sulphur radicals during SAM growth by adding a radical trap (TEMPO or DMPO) into the solution. The resulting slower rates of SAM formation as well as lower coverage were in line with a radical-based mechanism. However further experiments are needed to confirm such a hypothesis. A third possibility is that the electric field at the interface may, at slightly negative potential, increase the affinity binding and promote the right orientation of the disulphide dipole for the binding to the gold surface ${ }^{60}$ Again, a reversed process could be expected by switching the applied potential to slightly positive values.

\section{CONCLUSION}

We have demonstrated that the formation of thioctic-based SAMs on a polycrystalline gold electrode can be unexpectedly facilitated by the application of a moderate cathodic potential ($0.4 \mathrm{~V}$ in $\left.\mathrm{CH}_{3} \mathrm{CN}\right)$ and totally impeded under a slightly anodic potential $\left(+0.5 \mathrm{~V}\right.$ in $\left.\mathrm{CH}_{3} \mathrm{CN}\right)$, thereby allowing to literally switching on/off the SAM formation under very "soft" conditions. The absence of a discernible transient faradaic response during the potential-assisted adsorption of the cyclic disulphide led us to conclude that THE adsorption reaction mechanism is not related to an electrochemical reduction with a net flow of electrons trough the metal. This is also probably the case for the potential-assisted desorption process. These results open the question about the nature of the mechanism involved in the facilitated formation of thioctic-based SAM under slightly negative potential. Work is in progress for elucidating this mechanism. To explain the striking antagonist behavior between the facilitated deposition of $n$-alkanethiols on a gold 
electrode polarized at $+0.5 \mathrm{~V}$ and the facilitated desorption of thioctic-based SAM at the same potential, we propose an energetically favored release of the thioctic-based SAM through homolytic cleavage of the Au-S bond followed by intramolecular cyclization of the generated thiyl diradicals.

The electrochemical methodology of in situ and real time monitoring of the chemisorption of a redox-labeled sulphur-containing molecule finally appears to be a very powerful approach for characterizing the growth rate of SAMs on gold under controlled potential. The method has the main advantages of been highly quantitative, sensitive and specific in respect of the deposited compound, as well as possessing a high temporal resolution. We now intend to take advantage of this methodology for characterizing in detail the kinetics of SAM growth from different redox-labeled sulphur-containing compounds on polarized electrodes and in different solvents. The adsorption progress curves included in the present work already suggest adsorption kinetics that does not follow a standard Langmuir kinetics model. Finally, the possibility to easily and selectively address the adsorption/desorption of thioctic-based SAMs on gold by applying moderate cathodic/anodic potentials adds a new degree of control and flexibility into their self-assembly, nanostructuration, and/or release.

\section{EXPERIMENTAL SECTION}

Materials and instrumentation. Thioctic acid, ferrocene carboxylic acid, DMAP, DCC, tetrabutylammonium tetrafluoroborate $\left(\mathrm{TBABF}_{4}\right)$, 6-bromo-1-hexanol, potassium thioacetate, acetyl chloride and all solvents were purchased from Sigma/Aldrich, Acros and Alfa Aesar and used as received without FURTHER purification. ${ }^{1} \mathrm{H}$ and ${ }^{13} \mathrm{C}$ NMR spectra were recorded on a Bruker AC $400 \mathrm{MHz}$. Mass spectra were recorded with a Trace GC coupled with a DSQ II. 
Cyclic voltammetry and chronoamperometry experiments were done with an Autolab potentiostat, PGSTAT 302N (Metrohm, Switzerland), controlled from an external PC equipped with the NOVA v1.8 and v1.9 software (Metrohm).

Synthesis of (1,2-dithiolan-3-yl)pentyl ferrocenecarboxylate. To a solution of ferrocene carboxylic acid $(56 \mathrm{mg}, 0.26 \mathrm{mmol})$ in dry $\mathrm{CH}_{2} \mathrm{Cl}_{2}(40 \mathrm{~mL})$ were added the lipoic alcohol (50 $\mathrm{mg}, 0.26 \mathrm{mmol}$ ) and DMAP (8 $\mathrm{mg}, 0.07 \mathrm{mmol})$. The mixture was then stirred at room temperature for $30 \mathrm{~min}$ and then cooled to $0^{\circ} \mathrm{C}$. At this temperature, a solution of DCC (54 mg, $0.26 \mathrm{mmol})$ in $\mathrm{CH}_{2} \mathrm{Cl}_{2}(35 \mathrm{~mL})$ was slowly added. The solution was then stirred at $\mathrm{RT}$ for 2 days. After extraction $\left(\mathrm{CH}_{2} \mathrm{Cl}_{2} / \mathrm{H}_{2} \mathrm{O}\right)$, the organic phases were dried over $\mathrm{MgSO}_{4}$ and evaporated. The crude product was purified by column chromatography on silica gel (cyclohexane/ethyl acetate $8 / 2)$ to afford the desired compound as orange oil in $30 \%$ yield. ${ }^{1} \mathrm{H}$ NMR $\left(400 \mathrm{MHz}, \mathrm{CDCl}_{3}\right): \delta$ $(\mathrm{ppm})=1.33-1.45\left(\mathrm{~m}, 4 \mathrm{H}, \mathrm{O}\left(\mathrm{CH}_{2}\right)_{2} \mathrm{CH}_{2}\right.$ and $\left.\mathrm{O}\left(\mathrm{CH}_{2}\right)_{3} \mathrm{CH}_{2}\right), 1.54\left(\mathrm{~m}, 2 \mathrm{H}, \mathrm{OCH}_{2} \mathrm{CH}_{2}\right), 1.81(\mathrm{~m}$, 2H, SSCHCH $\left.H_{2}\right), 1.99\left(\mathrm{~m}, 1 \mathrm{H}, \mathrm{SSCH}_{2} \mathrm{CH}_{2}\right), 2.49\left(\mathrm{~m}, 1 \mathrm{H}, \mathrm{SSCH}_{2} \mathrm{CH}_{2}\right), 3.15\left(\mathrm{~m}, 2 \mathrm{H}, \mathrm{SSCH}_{2}\right), 3.62$ (m, 1H, SSCH), $4.22\left(\mathrm{~s}, 5 \mathrm{H}, \mathrm{H}_{\mathrm{Fc}}, \mathrm{CH}(\mathrm{Cp})\right), 4.23\left(\mathrm{t},{ }^{3} \mathrm{~J}_{(\mathrm{H}, \mathrm{H})}=8.10 \mathrm{~Hz}, 2 \mathrm{H}, \mathrm{FcCOOCH}_{2}\right), 4.41(\mathrm{~m}$, $\left.2 \mathrm{H}, \mathrm{H}_{\mathrm{Fc}}, \mathrm{CH}\right), 4.82\left(\mathrm{~m}, 2 \mathrm{H}, \mathrm{H}_{\mathrm{Fc}}, \mathrm{CH}\right) .{ }^{13} \mathrm{C}$ NMR $\left(100.6 \mathrm{MHz}, \mathrm{CDCl}_{3}\right): \delta(\mathrm{ppm})=26.9(\mathrm{~s}$, $\left.\mathrm{OCH}_{2} \mathrm{CH}_{2}\right), 28.8$ and $29.0\left(\mathrm{~s}, \mathrm{O}\left(\mathrm{CH}_{2}\right)_{2} \mathrm{CH}_{2}\right.$ and $\left.\mathrm{O}\left(\mathrm{CH}_{2}\right)_{3} \mathrm{CH}_{2}\right), 34.9$ (s, $\left.\mathrm{SSCHCH}{ }_{2}\right), 39.5$ (s, $\left.\mathrm{SSCH}_{2}\right), 40.4$ (s, $\left.\mathrm{SSCH}_{2} \mathrm{CH}_{2}\right), 56.6$ (s, $\left.\mathrm{SSCH}\right), 64.1$ (s, $\left.\mathrm{FcCOOCH}_{2}\right), 69.7\left(\mathrm{~s}, \mathrm{C}_{\mathrm{Fc}}, \mathrm{CH}(\mathrm{Cp})\right), 70.2$ and $71.2\left(\mathrm{~s}, \mathrm{C}_{\mathrm{Fc}}, C \mathrm{H}\right), 77.3\left(\mathrm{~s}, \mathrm{C}_{\mathrm{Fc}}, C \mathrm{q}\right), 171.1$ (s, FcCO). ESI Mass (EI+): for $\mathrm{C}_{19} \mathrm{H}_{24} \mathrm{~S}_{2} \mathrm{O}_{2} \mathrm{Fe}$, calculated $\mathrm{m} / \mathrm{z}=404.06$; found $\mathrm{m} / \mathrm{z}=404.0$.

Electrochemical experiments. The electrochemical measurements were performed in a standard one-compartment electrochemical cell maintained at $20^{\circ} \mathrm{C}$. A platinum wire was used as auxiliary electrode and a saturated calomel electrode (SCE) as reference. Polycrystalline gold disk electrodes (3-mm diameter) were employed as working electrodes. All electrochemical 
experiments were done in $0.1 \mathrm{M} \mathrm{TBABF}_{4}$ anhydrous acetonitrile carefully purged from dioxygen by argon bubbling. The gold electrode surfaces were mechanically polished with graded alumina from 0.1 to $0.05 \mu \mathrm{m}$, then successively ultrasonicated in acetone, water and ethanol, each during 3 minutes, and thereafter electrochemically polished in $0.5 \mathrm{M}$ sulphuric acid by applying 3 cyclic voltammetric scans between -0.1 and $1.5 \mathrm{~V}$ at $0.05 \mathrm{~V} / \mathrm{s}$. Finally, before use for electrochemical experiments, the gold electrodes were thoroughly rinsed with water and acetonitrile. The standard procedure we have used for in situ monitoring the SAM formation consists to immerse a freshly prepared gold electrode in an acetonitrile solution $\left(0.1 \mathrm{M}\right.$ of $\left.\mathrm{TBABF}_{4} / \mathrm{CH} 3 \mathrm{CN}\right)$ containing $1 \mu \mathrm{M}$ or $20 \mu \mathrm{M}$ of $\mathrm{FcCO}_{2} \mathrm{DT}$ and then, after immediate connection to the potentiostat, to initiate a programmed sequence in the NOVA software in such a way to iteratively repeat a start at a desired applied potential for a fixed period of time followed by a rapid CV scan from the starting applied potential up to the inverted potential of $+0.87 \mathrm{~V}$ and then back to the initial applied potential without opening the circuit. In the present work, the sequence was repeated every $13 \mathrm{~s}$ or $8 \mathrm{~s}$ during a whole period of time of $39 \mathrm{~min}$ or $40 \mathrm{~min}$, respectively, leading thus the recording of 180 or $300 \mathrm{CV}$ plots per experiment.

\section{ASSOCIATED CONTENT}

Supporting Information. Figures S1 to S5 showing CVs of a redox-active SAM on gold at different scan rates, normalized plots of the surface coverage and capacitance densities, potential-step experiments at a bare and a saturated $\mathrm{FcCO}_{2} \mathrm{DT}$-SAM-coated gold electrode, and theoretical transient current responses. This material is available free of charge via the Internet at http://pubs.acs.org. 


\section{AUTHOR INFORMATION}

Corresponding Author. Fax: +33157278788; Tel: +33157278789; E-mail: limoges@univparis-diderot.fr

\section{Notes}

${ }^{*}$ Disulfides are a class of compounds more stable to oxidation than thiols and also more readily available from commercial sources.

${ }^{\S}$ This represents a positive shift of $40 \mathrm{mV}$ compared to the homogenous solution, indicating a stabilization of the reduced form of ferrocene in the SAM.

${ }^{\dagger}$ It should be a problem to oxidize the ferrocene probe during the electrode polarization because ferrocenium is known to be poorly stable, notably in the presence of nucleophiles.

\section{ACKNOWLEDGMENTS}

The authors gratefully acknowledge the CNRS and the Ministère de l'Enseignement Supérieur et de la Recherche Scientifique (Tunisia) and the Ministère des Affaires Etrangères et Européennes (France) for financial support of this work through CNRS-DGRS 10 /R 1208 CMCU PHCUtique 11G-1202 and a grant « bourse d'alternance » for R.Sahli. We are also grateful to Dr. Sihem Groni for her support and to Dr. J-M. Savéant and Pr. M. Robert for helpful discussions and comments. 


\section{REFERENCES}

(1) Structure and growth of self-assembling monolayers, Schreiber, F. Prog. Surf. Sci. 2000, 65, 151-256.

(2) Self-Assembled Monolayers of Thiolates on Metals as a Form of Nanotechnology, Love, J. C.; Estroff, L. A.; Kriebel, J. K.; Nuzzo, R. G.; Whitesides, G. M. Chem. Rev. 2005, 105, 1103-1169.

(3) Electrochemistry of redox-active self-assembled monolayers, Eckermann, A. L.; Feld, D. J.; Shaw, J. A.; Meade, T. J. Coord. Chem. Rev. 2010, 254, 1769-1802.

(4) Self-assembled monolayers (SAMs) for electrochemical sensing, Mandler, D.; Kraus-Ophir, S. J. Solid State Electrochem. 2011, 15, 1535-1558.

(5) Finklea, H. O. In Electroanalytical Chemistry Vol 19; Electrochemistry of Organized Monolayers of Thiols and Related Molecules on Electrodes; 1996; A. J. Bard, I. Rubinstein, Eds.; Marcel Dekker Inc.: New York, pp 110-335.

(6) Kinetics of Formation of Long-Chain n-Alkanethiolate Monolayers on Polycrystalline Gold, Bensebaa, F.; Voicu, R.; Huron, L.; Ellis, T. H. Langmuir 1997, 13, 5335-5340.

(7) Adsorption and Desorption of Electroactive Self-Assembled Thiolate Monolayers on Gold, Voicu, R.; Ellis, T. H.; Ju, H.; Leech, D. Langmuir 1999, 15, 8170-8177.

(8) Formation of monolayer films by the spontaneous assembly of organic thiols from solution onto gold, Bain, C. D.; Troughton, E. B.; Tao, Y. Y.; Evall, J.; Whitesides, G. M.; Nuzzo, R. G. J. Am. Chem. Soc. 1989, 111, 321-335.

(9) Kinetics of alkanethiol adsorption on gold, Pan, W.; Durning, C. J.; Turro, N. J. Langmuir 1996, 12, 4469-4473.

(10) In Situ Kinetics of Self-Assembly by Surface Plasmon Resonance Spectroscopy, Peterlinz, K. A.; Georgiadis, R. Langmuir 1996, 12, 4731-4740.

(11) A Steady-State Kinetic Model Can Be Used to Describe the Growth of Self-Assembled Monolayers (SAMs) on Gold, Shon, Y.-S.; Lee, T. R. J. Phys. Chem. B 2000, 104, 8182-8191.

(12) Potential-Assisted Deposition of Alkanethiols on Au: Controlled Preparation of Single-and Mixed-Component SAMs, Ma, F.; Lennox, R. B. Langmuir 2000, 16, 6188-6190.

(13) Potential-assisted deposition of mixed alkanethiol self-assembled monolayers, Meunier-Prest, R.; Legay, G.; Raveau, S.; Chiffot, N.; Finot, E. Electrochim. Acta 2010, 55, 2712-2720.

(14) Effect of substrate potentials on the structural disorders of alkanethiol monolayers prepared by electrochemically directed assembly, Diao, P.; Hou, Q.; Guo, M.; Xiang, M.; Zhang, Q. J. Electroanal. Chem. 2006, 597, 103-110.

(15) Electrical Control of Alkanethiols Self-Assembly on a Gold Surface as an Approach for Preparation of Microelectrode Arrays, Riepl, M.; Mirsky, V. M.; Wolfbeis, O. S. Mikrochim. Acta 1999, 131, 29-34.

(16) Electrochemical Reactions in Adsorption of Organosulfur Molecules on Gold and Silver: Potential Dependent Adsorption, Paik, W.; Eu, S.; Lee, K.; Chon, S.; Kim, M. Langmuir 2000, 16, 10198-10205.

(17) Adsorption of self-assembling sulfur compounds through electrochemical reactions: Effects of potential, acid and oxidizing agents, Chon, S.; Paik, W. Phys. Chem. Chem. Phys. 2001, 3, 3405-3410.

(18) Multidentate Adsorbates for Self-Assembled Monolayer Films, Chinwangso, P.; Jamison, A. C.; Lee, T. R. Acc. Chem. Res. 2011, 44, 511-519.

(19) Synthesis of Compact Multidentate Ligands to Prepare Stable Hydrophilic Quantum Dot Fluorophores, Uyeda, H. T.; Medintz, I. L.; Jaiswal, J. K.; Simon, S. M.; Mattoussi, H. J. Am. Chem. Soc, 2005, 127, 3870-3878.

(20) Toward Reliable Gold Nanoparticle Patterning On Self-Assembled DNA Nanoscaffold, Sharma, J.; Chhabra, R.; Andersen, C. S.; Gothelf, K. V.; Yan, H.; Liu, Y. J. Am. Chem. Soc. 2008, 130, 7820-7821.

(21) Effects of Ligand Coordination Number and Surface Curvature on the Stability of Gold Nanoparticles in Aqueous Solutions, Mei; B. C.; Oh, E.; Susumu, K.; Farrell, D.; Mountziaris, T. J.; Mattoussi, H. Langmuir 2009, 25, 10604-10611.

(22) A study of adsorption kinetics and thermodynamics of $\omega$-mercaptoalkylhydroquinone self-assembled monolayer on a gold electrode, Hong, H-G.; Park, W. Electrochim. Acta 2005, 51, 579-587.

(23) Synthesis of adsorbable redox-active osmium thiol monolayers and the effects of the working electrode potential during deposition, Bretz, R. L.; Abruña, H. D. J. Electroanal. Chem. 1995, 388, 123-132.

(24) Adsorption of Short-Chain Thiols and Disulfides onto Gold under Defined Mass Transport Conditions: Coverage, Kinetics, and Mechanism, Rouhana, L. L.; Moussallem, M. D.; Schlenoff, J. B. J. Am. Chem. Soc. 2011, 133, 16080-16091.

(25) Self-Assembly of n-Alkanethiols: A Kinetic Study by Second Harmonic Generation, Dannenberger, O.; Buck, M.; Grunze, M. J. Phys. Chem. B 1999, 103, 2202-2213.

(26) Characterization of the Electron Transfer of a Ferrocene Redox Probe and a Histidine-Tagged Hemoprotein Specifically Bound to a Nitrilotriacetic-Terminated Self-Assembled Monolayer, Balland, V.; Lecomte, S.; Limoges, B. Langmuir 2009, 25, 6532-6542.

(27) Theoretical and Electrochemical Analysis of Dissociative Electron Transfers Proceeding through Formation of Loose Radical Anion Species: Reduction of Symmetrical and Unsymmetrical Disulfides, Antonello, S.; Benassi, R.; Gavioli, G.; Taddei, 
F.; Maran, F. J. Am. Chem. Soc. 2002, 124, 7529-7538.

(28) Primary steps of oxidation and electronic interactions in anodic cleavage of $\alpha, \omega$-diisocyanurate substituted dialkyl disulfides, Grogger, C.; Fattakhov, S.G.; Jouikov, V. V.; Shulaeva, M. M.; Reznik, V. S. Electrochim. Acta 2004, 49, $3185-3194$.

(29) Coadsorption of ferrocene-terminated and unsubstituted alkanethiols on gold: electroactive self-assembled monolayers, Chidsey, C. E. D.; Bertozzi, C. R.; Putvinski, T. M.; Mujsce, A. M. J. Am. Chem. Soc. 1990, 112, 4301-4306.

(30) General expression of the linear potential sweep voltammogram in the case of diffusionless electrochemical systems, Laviron, E. J. Electroanal. Chem. 1979, 101, 19-28.

(31) Magnetic Field Effects in Ferrocenealkane Thiol Self Assembled Monolayer Modified Electrodes, Lyons, M. E. G.; O'Brien, R.; Kinsella, M.; Mc Gloinn, C.; Scully, P. N. Int. J. Electrochem. Sci, 2010, 5, 1310-1341.

(32) Self-Assembling Bipyridinium Multilayers, Alvarado, R. J.; Mukherjee, J.; Pacsial, E. J.; Alexander, D.; Raymo, F. M. J. Phys. Chem. B 2005, 109, 6164-6173.

(33) The electrochemical desorption of n-alkanethiol monolayers from polycrystalline Au and Ag electrodes, Widrig, C. A.; Chung, C.; Porter, M. D. J. Electroanal. Chem. 1991, 310, 335-359.

(34) Electrochemical Desorption and Adsorption of Nonyl Mercaptan at Gold Single Crystal Electrode Surfaces, Yang, D. F.; Wilde, C. P.; Morin, M. Langmuir 1996, 12, 6570-6577.

(35) Voltammetric reductive desorption characteristics of alkanethiolate monolayers at single crystal Au(111) and (110) electrode surfaces, Zhong, C.-J.; Zak, J.; Porter, M. D. J. Electroanal. Chem. 1997, 421, 9-13.

(36) Electrochemical Stability of Self-Assembled Monolayers on Gold, Beulen, M. W. J.; Kastenberg, M. I.; Van Veggel, F. C. J. M.; Reinhoudt, D. N. Langmuir 1998, 14, 7463-7467.

(37) Electrochemical Oxidative Formation and Reductive Desorption of a Self-Assembled Monolayer of Decanethiol on a Au(111) Surface in KOH Ethanol Solution, Sumi, T.; Uosaki, K. J. Phys. Chem. B 2004, 108, 6422-6428.

(38) Self-Assembled Monolayers on Oxidized Metals. 3. Alkylthiol and Dialkyl Disulfide Assembly on Gold under Electrochemical Conditions, Ron, H.; Rubinstein, I. J. Am. Chem. Soc. 1998, 120, 13444-13452.

(39) Selective Anodic Desorption for Assembly of Different Thiol Monolayers on the Individual Electrodes of an Array, Collman, J. P.; Hosseini, A.; Eberspacher, T. A.; Chidsey, C. E. D. Langmuir 2009, 25, 6517-6521.

(40) Factors that influence the stability of self-assembled organothiols on gold under electrochemical conditions, Everett, W. R.; Fritsch-Faules, I. Anal. Chim. Acta 1995, 307, 253-268.

(41) Self-Assembled Monolayers from Organosulfur Compounds: A Comparison between Sulfides, Disulfides, and Thiols, Jung, C.; Dannenberger, O.; Xu, Y.; Buck, M.; Grunze, M. Langmuir 1998, 14, 1103-1107.

(42) Kinetics of Formation for n-Alkanethiolate Self-Assembled Monolayers onto Gold in Aqueous Micellar Solutions of C12E6 and C12E7, Yan, D.; Saunders, J. A.; Jennings, G. K. Langmuir 2002, 18, 10202-10212.

(43) A study of kinetics of adsorption of alkanethiols on gold using electrochemical impedance spectroscopy, Subramanian, R.; Lakshminarayanan, V. Electrochim. Acta 2000, 45, 4501-4509.

(44) Adsorption behavior of functionalized ferrocenylalkane thiols and disulfide onto Au and ITO and electrochemical properties of modified electrodes: Effects of acyl and alkyl groups attached to the ferrocene ring, Kondo, T.; Takechi, M.; Sato, Y.; Uosaki, K. J. Electroanal. Chem. 1995, 381, 203-209.

(45) Comparison of self-assembled monolayers on gold: coadsorption of thiols and disulfides, Bain, C. D.; Biebuyck, H. A.; Whitesides, G. M. Langmuir 1989, 5, 723-727.

(46) Comparison of Organic Monolayers on Polycrystalline Gold Spontaneously Assembled from Solutions Containing Dialkyl Disulfides or Alkanethiols, Biebuyck, H. A.; Bain, C. D.; Whitesides, G. M. Langmuir 1994, 10, 1825-1831.

(47) Ishida, T.; Yamamoto, S.; Mizutani, W.; Motomatsu, M.; Tokumoto, H.; Hokari, H.; Azehara, H.; Fujihira, M. Langmuir 1997, 13, 3261-3265.

(48) Stability and Self-Exchange in Alkanethiol Monolayers, Schlenoff, J. B.; Li, M.; Ly, H. J. Am. Chem. Soc. 1995, 117, 1252812536.

(49) Monitoring of the Self-Assembled Monolayer of 1-Hexadecanethiol on a Gold Surface at Nanomolar Concentration Using a Piezo-Excited Millimeter-Sized Cantilever Sensor, Campbell, G. A.; Mutharasan, R. Langmuir 2005, 21, 11568-11573.

(50) Quantitating the Balance between Enthalpic and Entropic Forces in Alkanethiol/Gold Monolayer Self Assembly, Schessler, H. M.; Karpovich, D. S.; Blanchard, G. J. J. Am. Chem. Soc. 1996, 118, 9645-9651.

(51) Active Spatiotemporal Control of Electrochemical Reactions by Coupling to In-Plane Potential Gradients, Balss, K. M.; Coleman, B. D.; Lansford, C. H.; Haasch, R. T.; Bohn, P. W. J. Phys. Chem. B 2001, 105, 8970-8978.

(52) Dynamic Monolayer Gradients: Active Spatiotemporal Control of Alkanethiol Coatings on Thin Gold Films, Terrill, R. H.; Balss, K. M.; Zhang, Y.; Bohn, P. W. J. Am. Chem. Soc. 2000, 122, 988-989.

(53) Patterned self-assembled alkanethiolate monolayers on gold. Patterning and imaging by means of scanning electrochemical microscopy, Wittstock, G.; Hesse, R.; Schuhmann, W. Electroanalysis 1997, 9, 746-750.

(54) Scanning probe lithography. 1. Scanning tunneling microscope induced lithography of self-assembled n-alkanethiol monolayer resists, Ross, C. B.; Sun, L.; Crooks, R. M. Langmuir 1993, 9, 632-636. 
(55) Electrochemically Addressable Functionalization and Parallel Readout of a DNA Biosensor Array, Niu, L.; Knoll, W. Anal. Chem. 2007, 79, 2695-2702.

(56) Electrochemically Directed Self-Assembly on Gold, Hsueh, C.-C.; Lee, M.-T.; Freund, M. S.; Ferguson, G. S. Angew. Chem. Int. Ed. 2000, 39, 1227-1230.

(57) Direct Route to Well-Defined, Chemically Diverse Electrode Arrays, Labukas, J. P.; Ferguson, G. S. Langmuir 2011, 27, 3219-3223.

(58) Electrochemical Patterning of Self-Assembled Monolayers onto Microscopic Arrays of Gold Electrodes Fabricated by Laser Ablatio, Tender, L. M.; Worley, R. L.; Fan, H. Y.; Lopez, G. P. Langmuir 1996, 12, 5515-5518.

(59) Photodegradable, Photoadaptable Hydrogels via Radical-Mediated Disulfide Fragmentation Reaction, Fairbanks, B. D.; Singh, S. P.; Bowman, C. N.; Anseth, K. S. Macromolecules 2011, 44, 2444-2450.

(60) Partial Electron Transfer in Octadecanethiol Binding to Gold, Krysinski, P.; Chamberlain, II R.V.; Majda, M. Langmuir 1994, 10, 4286-4294. 